\title{
Pre-exercise carbohydrate and fat ingestion: effects on metabolism and performance
}

\author{
MARK HARGREAVES, ${ }^{1 *}$ JOHN A. HAWLEY ${ }^{2}$ and ASKER JEUKENDRUP ${ }^{3}$ \\ ${ }^{1}$ Centre for Physical Activity and Nutrition Research, School of Health Sciences, Deakin University, Burwood, VIC \\ 3125, Australia, ${ }^{2}$ Exercise Metabolism Group, School of Medical Sciences, RMIT University, Bundoora, VIC 3083, \\ Australia and ${ }^{3}$ School of Sport and Exercise Sciences, University of Birmingham, Birmingham B15 2TT, UK
}

Accepted 7 August 2003

\begin{abstract}
A key goal of pre-exercise nutritional strategies is to maximize carbohydrate stores, thereby minimizing the ergolytic effects of carbohydrate depletion. Increased dietary carbohydrate intake in the days before competition increases muscle glycogen levels and enhances exercise performance in endurance events lasting $90 \mathrm{~min}$ or more. Ingestion of carbohydrate 3-4 h before exercise increases liver and muscle glycogen and enhances subsequent endurance exercise performance. The effects of carbohydrate ingestion on blood glucose and free fatty acid concentrations and carbohydrate oxidation during exercise persist for at least $6 \mathrm{~h}$. Although an increase in plasma insulin following carbohydrate ingestion in the hour before exercise inhibits lipolysis and liver glucose output, and can lead to transient hypoglycaemia during subsequent exercise in susceptible individuals, there is no convincing evidence that this is always associated with impaired exercise performance. However, individual experience should inform individual practice. Interventions to increase fat availability before exercise have been shown to reduce carbohydrate utilization during exercise, but do not appear to have ergogenic benefits.
\end{abstract}

Keywords: fatigue, free fatty acids, glucose uptake, insulin, muscle glycogen.

\section{Introduction}

The importance of carbohydrate for exercise performance has been recognized since the classic respiratory exchange studies of Christensen and Hansen in the late 1930s and the biopsy studies of Bergstrom and colleagues (Bergstrom et al., 1967), who measured muscle glycogen during various dietary and exercise interventions. Since then, considerable attention has focused on nutritional strategies to maximize endogenous carbohydrate stores (liver and muscle glycogen), thereby minimizing the potential ergolytic effects of carbohydrate depletion (Coyle et al., 1986). In this review, attention will focus on dietary carbohydrate during training in the days (17) leading up to competition and on carbohydrate and fat ingestion in the hours immediately before exercise and their effects on exercise metabolism and performance.

\footnotetext{
* Author to whom all correspondence should be addressed. e-mail: mharg@deakin.edu.au
}

\section{Carbohydrate loading in the days before exercise}

In the classic carbohydrate loading study of Bergstrom et al. (1967), the ingestion of a high carbohydrate diet, following a period of relative carbohydrate deprivation, resulted in a marked increase (supercompensation) in muscle glycogen (to as high as $200 \mathrm{mmol} \cdot \mathrm{kg}^{-1}$ wet mass) and enhanced subsequent endurance exercise performance. More recently, a less extreme dietexercise regimen was found to be equally effective in elevating pre-exercise muscle glycogen to these levels (Sherman et al., 1981), but had no effect on subsequent $21-\mathrm{km}$ running performance lasting $\sim 80 \mathrm{~min}$. Trained athletes were shown to increase their muscle glycogen to $180 \mathrm{mmol} \cdot \mathrm{kg}^{-1}$ wet mass in as little as one day by ingesting $10 \mathrm{~g}$ carbohydrate $\cdot \mathrm{kg}^{-1} \mathrm{BM}$ (where $\mathrm{BM}=$ body mass) and remaining inactive (Bussau et al., 2002). Muscle glycogen did not increase further during another 2 days of rest and high carbohydrate intake. There is also evidence that well-trained athletes can maintain, or even increase, their muscle glycogen stores to $170-180 \mathrm{mmol} \cdot \mathrm{kg}^{-1}$ wet mass in less than $24 \mathrm{~h}$ while training $\left(\sim 67 \% \dot{\mathrm{V}} \mathrm{O}_{2 \text { peak }}\right) 2 \mathrm{~h}$ per day and 
consuming $10-12.5 \mathrm{~g}$ carbohydrate $\cdot \mathrm{kg}^{-1} \mathrm{BM} \cdot$ day $^{-1}$ (Coyle et al., 2001). It has even been suggested that trained athletes can greatly increase their muscle glycogen stores in less than $24 \mathrm{~h}$ by performing only 3 min of supramaximal exercise and then consuming a high carbohydrate diet (Fairchild et al., 2002). This protocol potentially represents an improvement over previous regimens that have been tested extensively under laboratory and/or field conditions and further study is warranted. The mechanisms that allow trained individuals to rapidly increase muscle glycogen stores remain to be elucidated, but are likely to be related to their higher GLUT-4 concentrations and glycogen synthase activities (Hickner et al., 1997).

Despite a greater reliance on muscle glycogen when pre-exercise concentrations are elevated (Gollnick et al., 1972; Bosch et al., 1993; Hargreaves et al., 1995), increased dietary carbohydrate in the 1-7 days before exercise is generally associated with enhanced performance when exercise duration exceeds about $90 \mathrm{~min}$ (Galbo et al., 1979; Brewer et al., 1988; Fallowfield and Williams, 1993; Rauch et al., 1995; Hawley et al., 1997b; Pitsiladis and Maughan, 1999; Walker et al., 2000), probably due to a delay in the point at which muscle glycogen availability is limiting for optimal exercise performance. The largest effects are observed during exercise trials to exhaustion (often referred to as endurance 'capacity') and, while still apparent, they are smaller in magnitude during tests of endurance 'performance' that are not open-ended such as total work output in a given time or time taken to complete a certain distance or amount of work (Jeukendrup et al., 1996). During prolonged, strenuous exercise, rates of carbohydrate oxidation can be as high as $3-4 \mathrm{~g} \cdot \mathrm{min}^{-1}$, derived primarily from muscle glycogen (Angus et al., 2002). Assuming an active muscle mass of $\sim 10 \mathrm{~kg}$ during cycling, one could argue that endurance athletes should ensure their pre-event muscle glycogen concentrations are at least in the range of 150$200 \mathrm{mmol} \cdot \mathrm{kg}^{-1}$ wet mass, even when carbohydrate is to be supplemented during exercise. Interestingly, carbohydrate loading has also been associated with increased exercise performance in the heat (Pitsiladis and Maughan, 1999), a condition where carbohydrate availability is not usually thought to limit exercise performance. Carbohydrate loading does not appear to further increase exercise performance when carbohydrate availability is maintained high with a pre-exercise carbohydrate meal and carbohydrate ingestion during exercise (Burke et al., 2000b). Furthermore, while two studies have observed no additional benefit of carbohydrate ingestion during exercise in carbohydrate-loaded individuals (Flynn et al., 1987; Widrick et al., 1993), one study has observed potentiation (Kang et al., 1995). A key factor may be the extent to which blood glucose concentrations are maintained during exercise in the carbohydrate-loaded state without carbohydrate ingestion. In shorter, more intense exercise bouts lasting about $60-90 \mathrm{~min}$, the benefits of glycogen loading are not apparent (Sherman et al., 1981; Madsen et al., 1990; Hawley et al., 1997a,b), possibly due to muscle glycogen availability not being a limiting factor in the non-carbohydrate-loaded trial in this type of exercise.

During single bouts of high-intensity exercise, the effects of carbohydrate loading are somewhat equivocal. Some studies have observed enhanced performance with elevated muscle glycogen concentrations after increased dietary carbohydrate intake (Maughan and Poole, 1981; Maughan et al., 1997), while others have observed no benefit of elevated pre-exercise muscle glycogen (Vandenberghe et al., 1995; Hargreaves et al., 1997). In studies by Maughan and colleagues, the differences in performance were most obvious at the extremes of diet and may have been due as much to deleterious acid-base disturbances following consumption of a high fat-protein diet as to increased muscle glycogen availability following the high carbohydrate diet (Maughan et al., 1997). With repeated bouts of high-intensity exercise, increased muscle glycogen availability is associated with enhanced intermittent exercise performance (Balsom et al., 1999). Furthermore, increasing dietary carbohydrate intake from $\sim 300$ to $\sim 600 \mathrm{~g} \cdot$ day $^{-1}$ in the 2 days before exercise improved long-term, intermittent exercise performance (Bangsbo et al., 1992), while ingestion of $10 \mathrm{~g}$ carbohydrate $\cdot \mathrm{kg}^{-1} \mathrm{BM}$ improved intermittent running capacity during $22 \mathrm{~h}$ of recovery when compared with an isoenergetic diet without additional carbohydrate (Nicholas et al., 1997).

It has been suggested that females may have a reduced ability to increase muscle glycogen during a period of dietary carbohydrate loading (Tarnopolsky et al., 1995), although this observation may have been due to a lower energy intake in the female participants (Tarnopolsky et al., 2001). Other studies have not observed reduced muscle glycogen storage in female athletes (Walker et al., 2000; James et al., 2001). Thus, with adequate energy and carbohydrate intake, female athletes benefit from carbohydrate loading as much as male athletes.

\section{Carbohydrate ingestion 3-4 h before exercise}

Ingestion of a carbohydrate-rich meal (containing about 140-330 g carbohydrate) 3-4 h before exercise has been shown to increase muscle glycogen (Coyle et al., 1985) and enhance exercise performance (Sherman et al., 1989; Wright et al., 1991; Schabort et al., 1999). An increase in pre-exercise muscle glycogen is one ex- 
planation for the enhanced performance. Alternatively, because liver glycogen concentrations are substantially reduced after an overnight fast, ingestion of carbohydrate may increase these reserves and contribute, together with any ongoing absorption of the ingested carbohydrate, to the maintenance of blood glucose concentrations and improved performance during subsequent exercise (Casey et al., 2000). In contrast, other studies have observed no benefit to exercise performance of a high carbohydrate meal $4 \mathrm{~h}$ before exercise (Okano et al., 1996; Whitley et al., 1998).

Despite plasma glucose and insulin concentrations returning to basal levels, ingestion of carbohydrate in the hours before exercise often results in a transient fall in glucose with the onset of exercise, increased carbohydrate oxidation and a blunting of free fatty acid (FFA) mobilization (Coyle et al., 1985; Sherman et al., 1989). These metabolic perturbations can persist for up to $6 \mathrm{~h}$ after carbohydrate ingestion (Montain et al., 1991), but are not detrimental to exercise performance, with an increased carbohydrate availability apparently compensating for the greater carbohydrate utilization. No differences in exercise performance have been observed after ingestion of meals that produced marked differences in plasma glucose and insulin concentrations (Wee et al., 1999). The effects of a high carbohydrate meal 3-4 h before exercise on subsequent performance may be equivalent to those observed with carbohydrate ingestion during exercise (Chryssanthopoulos et al., 1994), although this is not always the case (Wright et al., 1991) and there may be some important metabolic differences. The combination of a preexercise carbohydrate meal and carbohydrate ingestion during exercise may further enhance exercise performance (Wright et al., 1991; Chryssanthopoulos and Williams, 1997). From a practical perspective, if access to carbohydrate during exercise is limited or nonexistent, ingestion of 200-300 g carbohydrate 3-4 h before exercise may be an effective strategy for enhancing carbohydrate availability during the subsequent exercise period. Furthermore, ingestion of carbohydrate may be effective in enhancing subsequent exercise performance when the recovery period is relatively short ( $\sim 4$ h; Fallowfield et al., 1995).

\section{Carbohydrate ingestion 30-60 $\mathrm{min}$ before exercise}

The ingestion of carbohydrate in the hour before exercise results in a large increase in plasma glucose and insulin concentrations. With the onset of exercise, however, there is a rapid fall in blood glucose concentration as a consequence of the combined stimulatory effects of hyperinsulinaemia and contractile activity on muscle glucose uptake and inhibition of the exercise-induced rise in liver glucose output (MarmyConus et al., 1996; Febbraio et al., 2000a,b), despite ongoing absorption of the ingested carbohydrate. An enhanced uptake and oxidation of blood glucose by skeletal muscle may account for the increased carbohydrate oxidation often observed after pre-exercise carbohydrate ingestion (Costill et al., 1977; Febbraio and Stewart, 1996; Coyle et al., 1997; Horowitz et al., 1997). In addition, an increase in muscle glycogenolysis has been reported by some researchers (Costill et al., 1977; Hargreaves et al., 1985; Febbraio et al., 2000b), although others have not observed such an effect (Levine et al., 1983; Fielding et al., 1987; Hargreaves et al., 1987; Febbraio and Stewart, 1996). The increase in plasma FFA concentrations with exercise is attenuated following pre-exercise carbohydrate ingestion, as a consequence of insulin-mediated inhibition of lipolysis (Horowitz et al., 1997). Fat oxidation is reduced because of the lower plasma FFA availability, but also as a result of inhibition of lipid oxidation within muscle (Coyle et al., 1997), since restoration of plasma FFA availability does not completely return fat oxidation to values seen during exercise in the fasted state (Horowitz et al., 1997). Co-ingestion of medium-chain triglyceride with carbohydrate, as a strategy to increase plasma FFA, has no effect on muscle glycogen use during subsequent exercise (Horowitz et al., 2000). Since these metabolic effects of pre-exercise carbohydrate ingestion are a consequence of hyperglycaemia and hyperinsulinaemia, there has been interest in strategies that minimize the changes in plasma glucose and insulin before exercise. These have included the ingestion of fructose (Levine et al., 1983; Hargreaves et al., 1985, 1987) or carbohydrate types other than glucose with differing glycaemic indices (Thomas et al., 1991; Febbraio and Stewart, 1996; Kirwan et al., 1998, 2001a,b; Sparks et al., 1998; DeMarco et al., 1999; Febbraio et al., 2000b; Jentjens and Jeukendrup, 2003), varying the carbohydrate load (Seifert et al., 1994; Jentjens et al., 2003) and ingestion schedule (Moseley et al., 2003; Short et al., 1997), the addition of fat (Horowitz and Coyle, 1993), or the inclusion of warm-up exercise in the pre-exercise period (Brouns et al., 1989). In general, while these various interventions modify the metabolic response to exercise, there appears to be no great advantage for exercise performance in blunting the pre-exercise glycaemic and insulinaemic responses.

The glycaemic responses during exercise preceded by carbohydrate ingestion are determined by several factors. These include the combined stimulatory effects of insulin and contractile activity on muscle glucose uptake, the balance of inhibitory and stimulatory effects of insulin and catecholamines, respec- 
tively, on liver glucose output, and the magnitude of ongoing intestinal absorption of glucose from the ingested carbohydrate (Kuipers et al., 1999). The occurrence of rebound hypoglycaemia in susceptible individuals does not appear to be related to insulin sensitivity (Jentjens and Jeukendrup, 2002) or to the exercise intensity (Achten and Jeukendrup, 2003). Thus, the aetiology of rebound hypoglycaemia remains unknown and susceptibility to this condition must be determined by personal experience. Since the inhibition of lipolysis and fat oxidation occurs with only small increases in plasma insulin - for example, after fructose (low glycaemic index) ingestion - it could be argued that if pre-exercise carbohydrate ingestion is the only mechanism by which an athlete can increase carbohydrate availability during exercise, they would be well advised to ingest a reasonable amount of carbohydrate (perhaps as much as $100 \mathrm{~g}$ ), without undue gastrointestinal distress, so as to compensate for the suppressed fat oxidation and to provide a pool of glucose that becomes available for use during the later stages of exercise.

The metabolic alterations associated with ingestion of carbohydrate in the 30-60 min before exercise have the potential to influence exercise performance. It has been postulated that the increase in muscle glycogenolysis observed previously (Costill et al., 1977) would result in an earlier onset of fatigue during exercise, as was suggested in a subsequent study (Foster et al., 1979). In contrast, every study since has shown either unchanged (Hargreaves et al., 1987; Febbraio and Stewart, 1996; Sparks et al., 1998; Febbraio et al., 2000b; Jentjens and Jeukendrup, 2003; Jentjens et al., 2003; Moseley et al., 2003) or enhanced (Gleeson et al., 1986; Sherman et al., 1991; Thomas et al., 1991; Kirwan et al., 1998) endurance exercise performance after the ingestion of carbohydrate in the hour before exercise. Thus, notwithstanding the well-documented metabolic effects of pre-exercise carbohydrate ingestion, and the possible negative consequences of hypoglycaemia in susceptible individuals, on balance there appears to be little evidence to support the practice of avoiding carbohydrate ingestion in the hour before exercise, provided sufficient carbohydrate is ingested. Having said that, individual practice must be determined on the basis of individual experience with various pre-exercise carbohydrate ingestion protocols. Finally, when carbohydrate is ingested during prolonged exercise, the glycaemic index of preexercise carbohydrate feedings has no effect on performance (Burke et al., 1998); indeed, carbohydrate ingestion during exercise may be a more effective strategy for enhancing exercise performance (Febbraio et al., 2000a) if this is the only option available to an athlete.

\section{Increased fat availability before exercise}

Another potential strategy to enhance endurance exercise performance is to increase fat availability acutely, with a view to reducing carbohydrate utilization during exercise, thereby delaying the onset of carbohydrate depletion and fatigue. Increased dietary fat intake over a 24 -h period increased muscle triglyceride stores, but reduced cycling time-trial performance, compared with a high carbohydrate diet (Starling et al., 1997). A longer period of 'fat adaptation' ( 5 days +1 day carbohydrate intake to normalize muscle glycogen) resulted in marked carbohydrate sparing during exercise bouts lasting 2-4 h, but subsequent exercise performance was not altered (Burke et al., 2000a; Carey et al., 2001). Furthermore, although trained athletes were able to perform intense interval training sessions on such a dietary regimen, they were associated with increased ratings of perceived exertion (Stepto et al., 2002). Ingestion of high fat meals and infusion of Intralipid, both in combination with heparin administration, are effective in raising plasma FFA concentrations and have been associated with reduced muscle glycogen utilization (Costill et al., 1977; Vukovich et al., 1993) and carbohydrate oxidation (Hawley et al., 2000). One study has observed increased endurance with elevated plasma FFA before exercise (Pitsiladis et al., 1999), while others have not seen any benefit (Okano et al., 1996, 1998; Whitley et al., 1998; Hawley et al., 2000). Thus, it would appear that while such a strategy can have a marked effect on exercise metabolism (i.e. reduced carbohydrate utilization), there is no beneficial effect on exercise performance.

\section{Summary}

Increasing dietary carbohydrate intake to $\sim 10 \mathrm{~g} \cdot \mathrm{kg}^{-1}$ $\mathrm{BM}$ in the days leading up to athletic competition increases muscle glycogen stores and is associated with enhanced endurance exercise capacity and performance in events lasting more than $90 \mathrm{~min}$. While the performance of a single high-intensity effort does not appear to be improved by carbohydrate loading, intermittent high-intensity performance may be enhanced. Female and male athletes benefit equally from carbohydrate loading, provided energy and carbohydrate intake are adequate. Ingestion of a carbohydraterich (about 200-300 g carbohydrate) meal after an overnight fast and $2-4 \mathrm{~h}$ before exercise can replenish endogenous carbohydrate reserves and is associated with improved performance. On balance, the literature indicates that ingestion of carbohydrate in the hour before exercise does not impair exercise performance. However, there may be individuals who are susceptible 
to hypoglycaemia and its negative consequences. There are no clear indicators of susceptibility to rebound hypoglycaemia during exercise and this should be assessed by individual experience. Increasing fat availability before exercise reduces carbohydrate utilization during subsequent exercise, but does not alter exercise performance.

\section{References}

Achten, J. and Jeukendrup, A.E. (2003). Effects of preexercise ingestion of carbohydrate on glycaemic and insulinaemic responses during subsequent exercise at differing intensities. European Fournal of Applied Physiology, 88, 466-471.

Angus, D.J., Febbraio, M.A. and Hargreaves, M. (2002). Plasma glucose kinetics during prolonged exercise in trained humans when fed carbohydrate. American fournal of Physiology, 283, E573-E577.

Balsom, P.D., Gaitanos, G.C., Söderlund, K. and Ekblom, B. (1999). High-intensity exercise and muscle glycogen availability in humans. Acta Physiologica Scandinavica, 165, 337-345.

Bangsbo, J., Nørragaard, L. and Thorsøe, F. (1992). The effect of carbohydrate diet on intermittent exercise performance. International fournal of Sports Medicine, 13, 152-157.

Bergstrom, J., Hermansen, L., Hultman, E. and Saltin, B. (1967). Diet, muscle glycogen and physical performance. Acta Physiologica Scandinavica, 71, 140-150.

Bosch, A.N., Dennis, S.C. and Noakes, T.D. (1993). Influence of carbohydrate loading on fuel substrate turnover and oxidation during prolonged exercise. Fournal of Applied Physiology, 74, 1921-1927.

Brewer, J., Williams, C. and Patton, A. (1988). The influence of high carbohydrate diets on endurance running performance. European fournal of Applied Physiology, 57, 698-706.

Brouns, F., Rehrer, N.J., Saris, W.H.M., Beckers, E., Menheere, P. and ten Hoor, F. (1989). Effect of carbohydrate intake during warming-up on the regulation of blood glucose during exercise. International fournal of Sports Medicine, 10, S68-S75.

Burke, L.M., Claassen, A., Hawley, J.A. and Noakes, T.D. (1998). Carbohydrate intake during prolonged cycling minimizes effect of glycemic index of preexercise meal. Fournal of Applied Physiology, 85, 2220-2226.

Burke, L.M., Angus, D.J., Cox, G.R., Cummings, N.K., Febbraio, M.A., Gawthorn, K., Hawley, J.A., Minehan, M., Martin, D.T. and Hargreaves, M. (2000a). Effect of fat adaptation and carbohydrate restoration on metabolism and performance during prolonged cycling. Fournal of Applied Physiology, 89, 2413-2421.

Burke, L.M., Hawley, J.A., Schabort, E.J., St. Clair Gibson, A., Mujika, I. and Noakes, T.D. (2000b). Carbohydrate loading failed to improve $100-\mathrm{km}$ cycling perfomance in a placebo-controlled trial. Fournal of Applied Physiology, 88, 1284-1290.
Bussau, V.A., Fairchild, T.J., Rao, A., Steele, P. and Fournier, P.A. (2002). Carbohydrate loading in human muscle: an improved 1 day protocol. European fournal of Applied Physiology, 87, 290-295.

Carey, A.L., Staudacher, H.M., Cummings, N.K., Stepto, N.K., Nikolopoulos, V., Burke, L.M. and Hawley, J.A. (2001). Effects of fat adaptation and carbohydrate restoration on prolonged endurance exercise. Fournal of Applied Physiology, 91, 115-122.

Casey, A., Mann, R., Banister, K., Fox, J., Morris, P.G., MacDonald, I.A. and Greenhaff, P.L. (2000). Effect of carbohydrate ingestion on glycogen resynthesis in human liver and skeletal muscle, measured by ${ }^{13} \mathrm{C}$ MRS. American fournal of Physiology, 278, E65-E75.

Chryssanthopoulos, C. and Williams, C. (1997). Preexercise carbohydrate meal and endurance capacity when carbohydrates are ingested during exercise. International Fournal of Sports Medicine, 18, 543-548.

Chryssanthopoulos, C., Williams, C., Wilson, W., Asher, L. and Hearne, L. (1994). Comparison between carbohydrate feedings before and during exercise on running performance during a $30-\mathrm{km}$ treadmill time trial. International Fournal of Sport Nutrition, 4, 374-386.

Costill, D.L., Coyle, E., Dalsky, G., Evans, W., Fink, W. and Hoopes, D. (1977). Effects of elevated plasma FFA and insulin on muscle glycogen usage during exercise. Fournal of Applied Physiology, 43, 695-699.

Coyle, E.F., Coggan, A.R., Hemmert, M.K., Lowe, R.C. and Walters, T.J. (1985). Substrate usage during prolonged exercise following a preexercise meal. Fournal of Applied Physiology, 59, 429-433.

Coyle, E.F., Coggan, A.R., Hemmert, M.K. and Ivy, J.L. (1986). Muscle glycogen utilization during prolonged strenuous exercise when fed carbohydrate. Fournal of Applied Physiology, 61, 165-172.

Coyle, E.F., Jeukendrup, A.E., Wagenmakers, A.J.M. and Saris, W.H.M. (1997). Fatty acid oxidation is directly regulated by carbohydrate metabolism during exercise. American fournal of Physiology, 273, E268-E275.

Coyle, E.F., Jeukendrup, A.E., Oseto, M.C., Hodgkinson, B.J. and Ivy, J.L. (2001). Low-fat diet alters intramuscular substrates and reduces lipolysis and fat oxidation during exercise. American fournal of Physiology, 280, E391-E398.

DeMarco, H.M., Sucher, K.P., Cisar, C.J. and Butterfield, G.E. (1999). Pre-exercise carbohydrate meals: application of glycemic index. Medicine and Science in Sports and Exercise, 31, 164-170.

Fairchild, T.J., Fletcher, S., Steele, P., Goodman, C., Dawson, B. and Fournier, P.A. (2002). Rapid carbohydrate loading after a short bout of near maximal-intensity exercise. Medicine and Science in Sports and Exercise, 34, 980-986.

Fallowfield, J.L. and Williams, C. (1993). Carbohydrate intake and recovery from prolonged exercise. International Fournal of Sport Nutrition, 3, 150-164.

Fallowfield, J.L., Williams, C. and Singh, R. (1995). The influence of ingesting a carbohydrate-electrolyte beverage during 4 hours of recovery on subsequent endurance capacity. International fournal of Sport Nutrition, 5, 285299. 
Febbraio, M.A. and Stewart, K.L. (1996). CHO feeding before prolonged exercise: effect of glycemic index on muscle glycogenolysis and exercise performance. Fournal of Applied Physiology, 81, 1115-1120.

Febbraio, M.A., Chiu, A., Angus, D.J., Arkinstall, M.J. and Hawley, J.A. (2000a). Effects of carbohydrate ingestion before and during exercise on glucose kinetics and performance. Fournal of Applied Physiology, 89, 22202226.

Febbraio, M.A., Keenan, J., Angus, D.J., Campbell, S.E. and Garnham, A.P. (2000b). Preexercise carbohydrate ingestion, glucose kinetics, and muscle glycogen use: effect of the glycemic index. Fournal of Applied Physiology, 89, 1845-1851.

Fielding, R.A., Costill, D.L., Fink, W.J., King, D.S., Kovaleski, J.E. and Kirwan, J.P. (1987). Effects of preexercise carbohydrate feedings on muscle glycogen use during exercise in well-trained runners. European fournal of Applied Physiology, 56, 225-229.

Flynn, M.G., Costill, D.L., Hawley, J.A., Fink, W.J., Neufer, P.D., Fielding, R.A. and Sleeper, M.G. (1987). Influence of selected carbohydrate drinks on cycling performance and glycogen use. Medicine and Science in Sports and Exercise, 19, 37-40.

Foster, C., Costill, D.L. and Fink, W.J. (1979). Effects of pre-exercise feedings on endurance performance. Medicine and Science in Sports, 11, 1-5.

Galbo, H., Holst, J.J. and Christensen, N.J. (1979). The effect of different diets and of insulin on the hormonal response to prolonged exercise. Acta Physiologica Scandinavica, 107, 19-32.

Gleeson, M., Maughan, R.J. and Greenhaff, P.L. (1986). Comparison of the effects of preexercise feeding of glucose, glycerol and placebo on endurance performance and fuel homeostasis in man. European fournal of Applied Physiology, 55, 645-653.

Gollnick, P.D., Piehl, K., Saubert, C.W., Armstrong, R.B. and Saltin, B. (1972). Diet, exercise, and glycogen changes in human muscle fibres. Fournal of Applied Physiology, 33, 421-425.

Hargreaves, M., Costill, D.L., Katz, A. and Fink, W.J. (1985). Effect of fructose ingestion on muscle glycogen usage during exercise. Medicine and Science in Sports and Exercise, 17, 360-363.

Hargreaves, M., Costill, D.L., Fink, W.J., King, D.S. and Fielding, R.A. (1987). Effect of pre-exercise carbohydrate feedings on endurance cycling performance. Medicine and Science in Sports and Exercise, 19, 33-36.

Hargreaves, M., McConell, G.M. and Proietto, J. (1995). Influence of muscle glycogen on glycogenolysis and glucose uptake during exercise. Fournal of Applied Physiology, 78, 288-292.

Hargreaves, M., Finn, J.P., Withers, R.T., Halbert, J.A., Scroop, G.C., Mackay, M., Snow, R.J. and Carey, M.F. (1997). Effect of muscle glycogen availability on maximal exercise performance. European fournal of Applied Physiology, 75, 188-192.
Hawley, J.A., Palmer, G.S. and Noakes, T.D. (1997). Effects of 3 days of carbohydrate supplementation on muscle glycogen content and utilisation during a 1-h cycling performance. European fournal of Applied Physiology, 75, 407-412.

Hawley, J.A., Schabort, E.J., Noakes, T.D. and Dennis, S.C. (1997). Carbohydrate-loading and exercise performance: an update. Sports Medicine, 24, 73-81.

Hawley, J.A., Burke, L.M., Angus, D.J., Fallon, K.E., Martin, D.T. and Febbraio, M.A. (2000). Effect of altering substrate availability on metabolism and performance during intense exercise. British fournal of Nutrition, 84, 829-838.

Hickner, R.C., Fisher, J.S., Hansen, P.A., Racette, S.B., Mier, C.M., Turner, M.J. and Holloszy, J.O. (1997). Muscle glycogen accumulation after endurance exercise in trained and untrained individuals. Fournal of Applied Physiology, 83, 897-903.

Horowitz, J.F. and Coyle, E.F. (1993). Metabolic responses to preexercise meals containing various carbohydrates and fat. American fournal of Clinical Nutrition, 58, 235-241.

Horowitz, J.F., Mora-Rodríguez, R., Byerley, L.O. and Coyle, E.F. (1997). Lipolytic suppression following carbohydrate ingestion limits fat oxidation. American Fournal of Physiology, 273, E768-E775.

Horowitz, J.F., Mora-Rodríguez, R., Byerley, L.O. and Coyle, E.F. (2000). Preexercise medium-chain triglyceride ingestion does not alter muscle glycogen use during exercise. Fournal of Applied Physiology, 88, 219-225.

James, A.P., Lorraine, M., Cullen, D., Goodman, C., Dawson, B., Palmer, T.N. and Fournier, P.A. (2001). Muscle glycogen supercompensation: absence of a genderrelated difference. European Fournal of Applied Physiology, 85, 533-538.

Jentjens, R.L.P.G. and Jeukendrup, A.E. (2002). Prevalance of hypoglycemia following pre-exercise carbohydrate ingestion is not accompanied by higher insulin sensitivity. International fournal of Sport Nutrition and Exercise Metabolism, 12, 444-459.

Jentjens, R.L.P.G. and Jeukendrup, A.E. (2003). Effects of pre-exercise ingestion of trehalose, galactose and glucose on subsequent metabolism and cycling performance. European fournal of Applied Physiology, 88, 459-465.

Jentjens, R.L.P.G., Cale, C., Gutch, C. and Jeukendrup, A.E. (2003). Effects of pre-exercise ingestion of differing amounts of carbohydrate on subsequent metabolism and cycling performance. European Fournal of Applied Physiology, 88, 444-452.

Jeukendrup, A.E., Saris, W.H.M., Brouns, F. and Kester, A.D.M. (1996). A new validated endurance performance test. Medicine and Science in Sports and Exercise, 28, 266-270.

Kang, J., Robertson, R.J., Denys, B.G., DaSilva, S.G., Visich, P., Siminski, R.R., Utter, A.C., Goss, F.L. and Metz, K.F. (1995). Effect of carbohydrate ingestion subsequent to carbohydrate supercompensation on endurance performance. International fournal of Sport Nutrition, 5, 329-343. 
Kirwan, J.P., O'Gorman, D. and Evans, W.J. (1998). A moderate glycemic meal before endurance exercise can enhance performance. Fournal of Applied Physiology, 84, 53-59.

Kirwan, J.P., Cyr-Campbell, D., Campbell, W.W., Scheiber, J. and Evans, W.J. (2001a). Effects of moderate and high glycemic index meals on metabolism and exercise performance. Metabolism, 50, 849-855.

Kirwan, J.P., O'Gorman, D., Cyr-Campbell, D., Campbell, W.W., Yarasheski, K.E. and Evans, W.J. (2001b). Effects of a moderate glycemic meal on exercise duration and substrate utilization. Medicine and Science in Sports and Exercise, 33, 1517-1523.

Kuipers, H., Fransen, E.J. and Keizer, H.A. (1999). Preexercise ingestion of carbohydrate and transient hypoglycemia during exercise. International fournal of Sports Medicine, 20, 227-231.

Levine, L., Evans, W.J., Cadarette, B.S., Fisher, E.C. and Bullen, B.A. (1983). Fructose and glucose ingestion and muscle glycogen use during submaximal exercise. Fournal of Applied Physiology, 55, 1767-1771.

Madsen, K., Pedersen, P.K., Rose, P. and Richter, E.A. (1990). Carbohydrate supercompensation and muscle glycogen utilization during exhaustive running in highly trained athletes. European Fournal of Applied Physiology, 61, 467-472.

Marmy Conus, N., Fabris, S., Proietto, J. and Hargreaves, M. (1996). Pre-exercise glucose ingestion and glucose kinetics during exercise. Fournal of Applied Physiology, 81, 853-857.

Maughan, R.J. and Poole, D.C. (1981). The effects of a glycogen-loading regimen on the capacity to perform anaerobic exercise. European fournal of Applied Physiology, 46, 211-219.

Maughan, R.J., Greenhaff, P.L., Leiper, J.B., Ball, D., Lambert, C.P. and Gleeson, M. (1997). Diet composition and the performance of high-intensity exercise. Fournal of Sports Sciences, 15, 265-275.

Montain, S.J., Hopper, M.K., Coggan, A.R. and Coyle, E.F. (1991). Exercise metabolism at different time intervals after a meal. Fournal of Applied Physiology, 70, 882-888.

Moseley, L., Lancaster, G.I. and Jeukendrup, A.E. (2003). Effects of timing of pre-exercise ingestion of carbohydrate on subsequent metabolism and cycling performance. European Fournal of Applied Physiology, 88, 453-458.

Nicholas, C.W., Green, P.A., Hawkins, R.D. and Williams, C. (1997). Carbohydrate intake and recovery of intermittent running capacity. International fournal of Sport Nutrition, 7, 251-260.

Okano, G., Sato, Y., Takumi, Y. and Sugawara, M. (1996). Effect of $4 \mathrm{~h}$ preexercise high carbohydrate and high fat meal ingestion on endurance performance and metabolism. International Fournal of Sports Medicine, 17, 530-534.

Okano, G., Sato, Y. and Murata, Y. (1998). Effect of elevated blood FFA levels on endurance performance after a single fat meal ingestion. Medicine and Science in Sports and Exercise, 30, 763-768.
Pitsiladis, Y.P. and Maughan, R.J. (1999). The effects of exercise and diet manipulation on the capacity to perform prolonged exercise in the heat and in the cold in trained humans. Fournal of Physiology, 517, 919-930.

Pitsiladis, Y.P., Smith, I. and Maughan, R.J. (1999). Increased fat availability enhances the capacity of trained individuals to perform prolonged exercise. Medicine and Science in Sports and Exercise, 31, 1570-1579.

Rauch, L.H.G., Rodger, I., Wilson, G.R., Belonje, J.D., Dennis, S.C., Noakes, T.D. and Hawley, J.A. (1995). The effects of carbohydrate loading on muscle glycogen content and cycling performance. International fournal of Sport Nutrition, 5, 25-36.

Schabort, E.J., Bosch, A.N., Weltan, S.M. and Noakes, T.D. (1999). The effect of a pre-exercise meal on time to fatigue during prolonged cycling exercise. Medicine and Science in Sports and Exercise, 31, 464-471.

Seifert, J.G., Paul, G.L., Eddy, D.E. and Murray, R. (1994). Glycemic and insulinemic response to preexercise carbohydrate feedings. International fournal of Sport Nutrition, 4, 46-53.

Sherman, W.M., Costill, D.L., Fink, W.J. and Miller, J.M. (1981). Effect of exercise-diet manipulation on muscle glycogen and its subsequent utilization during performance. International fournal of Sports Medicine, 2, 114-118.

Sherman, W.M., Brodowicz, G., Wright, D.A., Allen, W.K., Simonsen, J. and Dernbach, A. (1989). Effects of $4 \mathrm{~h}$ preexercise carbohydrate feedings on cycling performance. Medicine and Science in Sports and Exercise, 21, 598-604.

Sherman, W.M., Peden, M.C. and Wright, D.A. (1991). Carbohydrate feedings $1 \mathrm{~h}$ before exercise improve cycling performance. American Fournal of Clinical Nutrition, 54, 866-870.

Short, K.R., Sheffield-Moore, M. and Costill, D.L. (1997). Glycemic and insulinemic responses to multiple preexercise carbohydrate feedings. International fournal of Sport Nutrition, 7, 128-137.

Sparks, M.J., Selig, S.E. and Febbraio, M.A. (1998). Preexercise carbohydrate ingestion: effect of the glycemic index on endurance exercise performance. Medicine and Science in Sports and Exercise, 30, 844-849.

Starling, R.D., Trappe, T.A., Parcell, A.C., Kerr, C.G., Fink, W.J. and Costill, D.L. (1997). Effects of diet on muscle triglyceride and endurance performance. Fournal of Applied Physiology, 82, 1185-1189.

Stepto, N.K., Carey, A.L., Staudacher, H.M., Cummings, N.K., Burke, L.M. and Hawley, J.A. (2002). Effect of short-term fat adaptation on high-intensity training. Medicine and Science in Sports and Exercise, 34, 449-455.

Tarnopolsky, M.A., Atkinson, S.A., Phillips, S.M. and MacDougall, J.D. (1995). Carbohydrate loading and metabolism during exercise in men and women. Fournal of Applied Physiology, 78, 1360-1368.

Tarnopolsky, M.A., Zawada, C., Richmond, L.B., Carter, S., Shearer, J., Graham, T. and Phillips, S.M. (2001). Gender differences in carbohydrate loading are related to energy intake. Fournal of Applied Physiology, 91, 225-230. 
Thomas, D.E., Brotherhood, J.R. and Brand, J.C. (1991). Carbohydrate feeding before exercise: effect of glycemic index. International Fournal of Sports Medicine, 12, 180186.

Vandenberghe, K., Hespel, P., Vanden Eynde, B., Lysens, R. and Richter, E.A. (1995). No effect of glycogen level on glycogen metabolism during high intensity exercise. Medicine and Science in Sports and Exercise, 27, 1278-1283.

Vukovich, M.D., Costill, D.L., Hickey, M.S., Trappe, S.W., Cole, K.J. and Fink, W.J. (1993). Effect of fat emulsion infusion and fat feeding on muscle glycogen utilisation during cycle exercise. Fournal of Applied Physiology, 75, 1513-1518.

Walker, J.L., Heigenhauser, G.J., Hultman, E. and Spriet, L.L. (2000). Dietary carbohydrate, muscle glycogen content, and endurance performance in well-trained women. Fournal of Applied Physiology, 88, 2151-2158.

Wee, S.-L., Williams, C., Gray, S. and Horabin, J. (1999). Influence of high and low glycemic index meals on endurance running capacity. Medicine and Science in Sports and Exercise, 31, 393-399.
Whitley, H.A., Humphreys, S.M., Campbell, I.T., Keegan, M.A., Jayanetti, T.D., Sperry, D.A., MacLaren, D.P., Reilly, T. and Frayn, K.N. (1998). Metabolic and performance responses during endurance exercise after high-fat and high-carbohydrate meals. Fournal of Applied Physiology, 85, 418-424.

Widrick, J.J., Costill, D.L., Fink, W.J., Hickey, M.S., McConell, G.K. and Tanaka, H. (1993). Carbohydrate feedings and exercise performance: effect of initial muscle glycogen concentration. Fournal of Applied Physiology, 74, 2998-3005.

Wright, D.A., Sherman, W.M. and Dernbach, A. (1991). Carbohydrate feedings before, during, or in combination improve cycling endurance performance. Fournal of Applied Physiology, 71, 1082-1088. 